Revista de Economia Política, vol. 23, $n^{\circ} 2$ (90), pp. 276-292, abril-junho/2003

\title{
A teoria institucional de Douglass North*
}

\author{
The institutional theory of Douglass North
}

PAULO GALA **

RESUMO: Este artigo tem por objetivo resenhar a teoria institucional de Douglass North. Após uma breve introdução e alguns comentários relacionados ao seu método, resume-se o core teórico que propõe a partir da análise de três de suas principais obras sobre o assunto. PALAVRAS-CHAVE: Retórica; nova economia institucional; Douglass North.

ABSTRACT: This paper aims to review the institutional theory of Douglass North. After a brief introduction and some comments related to his method, it sums up the theoretical core that proposes from the analysis of three of his main works on the subject.

KEYWORDS: Rethoric; new institutional economics; Douglass North.

JEL classification: B15; B31; B41.

Este artigo tem por objetivo resenhar a teoria institucional de Douglass North. Após uma breve introdução e alguns comentários relacionados ao seu método, resume-se o core teórico que propõe a partir da análise de três de suas principais obras sobre o assunto.

A partir da obtenção conjunta com Robert Fogel do Prêmio Nobel de 1993, Douglass North passou a ser referência importante para o estudo do desenvolvimento das economias no longo prazo. Numa obra com muitas incursões históricas e algumas inovações teóricas, o autor procura demonstrar como o crescimento de longo prazo, ou a evolução histórica, de uma sociedade é condicionado pela formação e evolução de suas instituições. Ligado ao grupo dos cliometristas norteamericanos, North torna-se conhecido na década de 60 pelos estudos de história econômica que desenvolve, com destaque para seu livro de 1966 The Economic Growth of the United States 1790-1860. Transita da análise de história econômica para estudos mais voltados à evolução de arranjos institucionais a partir de seu trabalho Sources of Productivity Change in Ocean Shipping, 1600-1850, de 1968 (Goldin, 1994: 8). Ao estudar a evolução da produtividade da indústria de trans-

\footnotetext{
* Este artigo é uma versão modificada de parte de dissertação de mestrado com o título "Teoria e Retórica em Douglass North: subsídios para uma análise de sua contribuição”, defendida em dezembro/2001 na FGV-SP, redigida sob a orientação do prof. dr. Luiz Carlos Bresser-Pereira.

* Mestre e doutorando em economia pela FGV-SP.
} 
porte oceânico num dado período, constata que evoluções institucionais foram mais importantes do que inovações tecnológicas. Desenvolve, em seguida, uma série de trabalhos procurando entender o papel das instituições na evolução das sociedades, que culminam no livro Institutions, Institutional Change and Economic Performance, de 1990.

Os estudos de Douglass North somados aos de Williamson, Coase, Demsetz, Alchian, entre outros, deram origem ao programa de pesquisa da Nova Economia Institucional (Rutherford, 1994: 2-3). O volume da literatura novo institucionalista é hoje crescente e, a se julgar pelo seu número de adeptos, pode-se dizer que essa corrente constitui-se num programa de pesquisa progressivo. Tendo em vista a importância de North como um dos fundadores desta agenda de pesquisa, este artigo procura contribuir para a discussão de sua obra a partir de uma leitura, entre outras possíveis, de três de seus principais livros sobre o assunto. Após um breve comentário acerca do método de North, iniciamos o estudo pelo livro The Rise of the Western World: A New Economic History, de 1973, escrito em co-autoria com Robert Paul Thomas, que contém a origem de seus principais insights. Passamos, em seguida, ao texto Structure and Change in Economic History, de 1981, que já acena com o esboço de uma teoria das instituições. Por fim, estudamos o livro de 1990, onde North procura formular um modelo institucional capaz de explicar movimentos seculares.

\section{ENTRE A TEORIA E A HISTÓRIA}

Para melhor entender a obra de Douglass North, precisamos capturar, de início, dois de seus principais movimentos ao longo do tempo. No primeiro, o autor migra da cliometria para a análise institucional. Como já vimos, a mudança se dá a partir do insight de que uma evolução institucional pode ser mais importante do que avanços tecnológicos para o desenvolvimento econômico. A transição fica clara na comparação entre os enfoques de seu livro de 1961 The Economic Growth of the United States 1790-1860 e de 1971 Institutional Change and American Economic Growth.

O segundo importante movimento ocorre nos subsequentes textos. Tomando por base estudos institucionais históricos, o autor dá passos no sentido de construir uma teoria econômica institucional. A partir da constatação e do entendimento do que foi o processo histórico do desenvolvimento econômico, procura formular uma teoria (institucional) do desenvolvimento econômico. Estuda a história de diversas civilizações ao longo do tempo - Egito, Grécia, Roma, Europa Feudal, Inglaterra entre outras - para ir, aos poucos, construindo uma teoria que possa auxiliar na explicação da evolução das sociedades (ver Macedo, 2001: 354).

Esse transitar entre o histórico e o teórico pode ser encontrado em todos os livros escritos a partir dos anos 70. Com o passar do tempo, North vai migrando de análises históricas para análises teóricas. Uma maneira simples de capturar esse movimento está na observação da divisão formal da estrutura de seus trabalhos. Em geral, divide seus livros em dois grandes blocos: teoria e história. A tabela 
abaixo ilustra a evolução que mencionamos por meio da comparação entre o espaço de texto formalmente reservado para discutir cada assunto em suas três principais obras:

\begin{tabular}{ccc}
\hline Obra & Análise Teórica & Análise Histórica \\
\hline $\begin{array}{c}\text { The Rise of the Western } \\
\text { World (North, 1973) }\end{array}$ & $\begin{array}{c}\text { Páginas 1 a 19 de um total } \\
\text { de 158-12\% }\end{array}$ & $\begin{array}{c}\text { Páginas 19 a 157 de um total } \\
\text { de 158 - 87\% }\end{array}$ \\
\hline $\begin{array}{c}\text { Structure and Change in } \\
\text { Economic History (North, 1981) }\end{array}$ & $\begin{array}{c}\text { Páginas 1 a 71 e 201 a 209 } \\
\text { de um total de 209-37\% }\end{array}$ & $\begin{array}{c}\text { Páginas 71 a 201 de um } \\
\text { total de 209-62\% }\end{array}$ \\
\hline $\begin{array}{c}\text { Intitutions, Institutional } \\
\text { Change and Economic } \\
\text { Performance (North, 1990) }\end{array}$ & $\begin{array}{c}\text { Páginas 1 a 140 de um total } \\
\text { de 140 - 100\% }\end{array}$ & $\begin{array}{c}\text { Exemplos em 140 páginas } \\
\text { sem espaço formalmente } \\
\text { separado - 0\% }\end{array}$ \\
\hline
\end{tabular}

\section{A ASCENSÃO DO MUNDO OCIDENTAL}

A base da proposta de North pode ser encontrada na leitura que faz do caso de sucesso das economias do Ocidente, notadamente da Europa Ocidental e Estados Unidos. Estas, segundo o autor, conseguiram desenvolver instituições capazes de atingir o crescimento econômico de longo prazo. O processo histórico do surgimento do capitalismo no mundo ocidental seria, portanto, a "matéria-prima" de seu trabalho The Rise of the Western World: A New Economic History, de 1973.

Em co-autoria com Robert Paul Thomas, procura mostrar como a Holanda e Inglaterra foram capazes de superar com sucesso as dificuldades impostas pela transição do feudalismo para o capitalismo. Para os autores, o grande avanço ocorrido nesses dois países, depois replicado pela porção ocidental do continente e mais à frente pela Nova Inglaterra, ocorre antes da chamada Revolução Industrial.

As instituições criadas no final da Idade Média pelas cidades holandesas e belgas — Bruges, Antuérpia, culminando com Amsterdã — em parte inspiradas em práticas de cidades italianas - Gênova, Veneza e Florença - e na sequência pelas principais cidades inglesas - Londres e Bristol - teriam sido capazes de levar ambos os países a um crescimento econômico nunca antes experimentado. Em seus termos, as sociedades dessas regiões teriam sido as primeiras a superar as "crises malthusianas", transformando o crescimento populacional em verdadeiro crescimento econômico, e não em crises de empobrecimento. Vejamos um pouco mais acerca dessa idéia de North.

A obra The Rise of the Western World gira em torno do conflito entre o aumento populacional e o esgotamento dos recursos físicos das sociedades no final do feudalismo. A partir dessa "tensão básica", North procura descrever o comportamento do ocidente europeu na saída da Idade Média. Em momentos de estabilidade social e política, como por exemplo nos séculos XII e XIII, o progresso eco- 
nômico desencadeava crescimento populacional. Esse crescimento, por sua vez, se desdobrava em desenvolvimento de novas instituições por um lado e empobrecimento relativo das populações por outro. O entendimento da transição do feudalismo no início do século XI para as vésperas da Revolução Industrial no século XVIII passa pela análise dessa tensão.

O crescimento populacional dos séculos XI e XII somado ao decorrente aumento do comércio provoca mudanças na estrutura institucional da Europa Ocidental, notadamente devido ao surgimento das cidades (ver North e Thomas, 1973: 12).

Contratos como a commenda e a societas, que envolviam a cooperação de um sócio investidor e um sócio "viajante", o ressurgimento de bancos de depósito e a criação de formas incipientes de bills of exchange e seguros significavam grandes avanços em termos da organização do processo produtivo. As feiras, como as de Champagne, mais do que praças comerciais, passavam a constituir-se em embriões de mercados de capitais.

Surgiam as sementes institucionais que estariam por trás do desenvolvimento econômico europeu subsequente. Com o renascimento comercial e urbano, parte das transações econômicas, antes restritas ao perímetro feudal, passariam a ser efetuadas nas cidades, dando origem aos mercados. Gradualmente o trabalho passaria a ser direcionado para a produção mercantil em detrimento de atividades de subsistência. Pouco a pouco, as cidades iriam ganhar espaço em relação aos feudos, trazendo grandes complicações ao arranjo institucional antes prevalecente. Os contratos de servidão feudais, por exemplo, passariam cada vez mais a competir com as incipientes relações mercantis presentes nos centros urbanos.

Essa evolução não seria, entretanto, linear. O grande progresso institucional observado dos 1000 aos 1300 é interrompido por um período de estagnação que vai pelo menos até meados dos 1400 . Retomando a tensão básica de North, se por um lado o crescimento populacional desencadeou uma série de inovações institucionais, notadamente o ressurgimento dos mercados, por outro, trouxe vários problemas ao cenário do oeste europeu, por conta do descompasso surgido entre a produção de alimentos e as necessidades de uma população crescente. Os retornos decrescentes da agricultura, decorrentes da ausência de inovações tecnológicas, fizeram com que muitas sociedades entrassem em colapso nesse período. Como bem aponta North, os séculos XIV e XV são marcados por fomes e pestes, por conta do aumento da pobreza relativa.

Um outro aspecto importante de sua tese encontra-se na discussão dos séculos XVI e XVII. Ao analisar o surgimento dos estados modernos, o autor procura demonstrar o que considera trajetórias institucionais bem-sucedidas. Os casos clássicos são Holanda e Inglaterra, que foram capazes de desenvolver arranjos institucionais para estimular atividades produtivas. O coração de seu argumento está na relação entre os estados que surgem nessas regiões e as organizações ou grupos produtivos locais. Nos países de sucesso, teria havido um equilíbrio de poder entre as monarquias e produtores que favoreceu a confecção de leis propícias ao desenvolvimento do comércio e da indústria. $\mathrm{Na}$ Espanha e França, principalmente na primeira, as leis e a organização institucional não teriam contribuído para o flores- 
cimento de atividades economicamente produtivas. Em geral, observamos nesses países, à época, uma legislação protetora de monopólios - como o caso das Mestas na Espanha - que não estimulava o surgimento de atividades rentáveis para a sociedade como um todo. O ponto relevante está na relação entre os estados que nasciam e a classe produtiva em geral. Mais especificamente, nas leis e regras que iam sendo geradas pelo sistema político para ordenar a atividade econômica. Como veremos adiante, o desempenho econômico das sociedades resultará sempre, em ultima análise, de suas dinâmicas institucionais.

Mas, enfim, do que depende e do que dependeu a prosperidade alcançada pelo mundo ocidental? Aqui tocamos o ponto crucial de sua contribuição, já presente no texto de 1973. Para se entender o desenvolvimento econômico sustentável de longo prazo, deve-se estudar as causas anteriores às tradicionais variáveis de crescimento. Para North, a chave do problema econômico não está no avanço tecnológico ou na acumulação de capital. Está nas regras ou arranjos institucionais que estimulam ou inibem atividades nesse sentido. $\mathrm{O}$ que a literatura econômica atual considera causas do crescimento nada mais são do que consequências de uma dada matriz institucional específica. No limite, as causas do crescimento, identificadas por essa visão, são o próprio crescimento (North e Thomas, 1973: 2).

O segredo para atingir o crescimento está na construção de uma matriz que estimule a acumulação de capital físico e humano. A grande distância observada ainda hoje entre países pobres e ricos encontra-se muito mais em diferenças entre matrizes institucionais do que em problemas de acesso a tecnologias. Sociedades pobres encontram-se nessa situação justamente por não terem desenvolvido uma base de regras, leis e costumes capazes de estimular atividades economicamente produtivas, especificamente acumulação de capital e de conhecimento.

O livro de 1973 procura justamente entender essa evolução institucional, que fez da Europa o berço da civilização ocidental. Observa-se isso a partir da saída da Idade Média. As instituições desenvolvidas originalmente na Itália e Holanda e seus desdobramentos levados a cabo principalmente pela Inglaterra colocam a civilização dessa porção do continente em posição privilegiada na saída do século XVIII. A proposição teórica de North de que as instituições estão na origem do processo de acumulação de capital e progresso tecnológico verifica-se na prática da história.

\section{OS RECORTES TEÓRICOS DE 1981}

Caminhando para a construção de um modelo mais coerente e fechado, North escreve o texto de 1981. Passa a distanciar-se ainda mais da perspectiva histórica em direção à teoria. Analisa, é certo, uma quantidade de situações históricas: a revolução do período Neolítico, os grandes impérios da Antiguidade, o Feudalismo, o surgimento da Europa Moderna, a Revolução Industrial, entre outros episódios. Certamente sua discussão não tem o detalhamento e rigor requeridos por estudos genuinamente históricos. Mas, justamente nesse ponto, encontramos a marca de North. Usa o histórico como alavanca para seus vôos teóricos (ver North e Davis, 1971: 4). 
Apesar de ainda não ter um teoria completamente acabada do desenvolvimento econômico e da evolução institucional, avança já com bastante força em termos analíticos. Por meio do conceito de structure presente no título da obra, procura captar teoricamente os diversos traços das sociedades com que se depara nas análises históricas. Para explicar a perfomance delas, teoriza sobre seus aspectos fundamentais: "political and economic institutions, technology, demography and ideology" (North, 1981: 3). Vejamos, já nos valendo — por questões didáticas — do texto de 1990 e de escritos posteriores, um pouco mais dos recortes teóricos que começam a se articular para formar o modelo que North irá propor.

\section{O papel da ideologia e o conceito de racionalidade}

Como veremos abaixo, o conceito de racionalidade que North utiliza jogará papel fundamental na construção de sua dinâmica institucional. Ao introduzir a noção de incerteza, tem o intuito de mostrar, já de início, sua rejeição pela rational choice. Argumenta o autor que os axiomas dessa teoria são muito rígidos e que sua adoção tem, de certo modo, impedido o avanço das ciências sociais (North, 1990: 17).

Como alternativa, propõe uma teoria de racionalidade mais ampla que dê conta dos dois principais problemas da rational choice a seu ver: i) a motivação dos agentes; ii) o problema da decifração do ambiente.

A impossibilidade de conhecer toda informação necessária para a tomada de decisões ótimas está na base da proposta do autor. Por problemas de complexidade e falta de capacidade computacional (North, 1990: 25) ou por questões de realidades mutáveis (North, 1999: 16), os agentes são incapazes de tomar decisões ótimas. É importante também frisar que o autor rejeita a noção de que, ao longo do processo decisório, mecanismos de feedback possam ser responsáveis pela correção de erros, fazendo com que, pelo menos no longo prazo, haja convergência entre as decisões dos agentes e os resultados considerados ótimos (North, 1990: 19).

Defenderá, assim, a utilização de uma racionalidade processual do tipo Herbert Simon como base para sua teoria de evolução institucional. A partir do momento em que os agentes não conhecem o mundo sobre o qual devem decidir, passam a construir "realidades subjetivas" dele e a atuar sob estas. Racionalidade não significa aqui atingir uma situação ótima, mas sim agir da maneira mais razoável possível na busca de determinados fins, dada a pobreza informacional. Na melhor das hipóteses, os agentes podem tentar aproximar sua visão de mundo - ideologia nos termos de North — da própria realidade objetiva.

Em termos motivacionais, a situação também não é simples. North argumenta que a maximização simplista da rational choice não consegue tratar de uma série de comportamentos pertinentes às ciências sociais. Seja por não explicar gestos altruísticos e cooperativos, seja por não levar em consideração dogmas, idéias e ideologias nas decisões dos atores, as behavioural assumptions of received theory parecem deixar muito a desejar na explicação de alguns fenômenos sociais e econômicos relevantes.

North não dá conta, entretanto, de propor uma teoria que seja capaz de supe- 
rar as críticas que levanta. Destaca o trabalho de Herbert Simon e Ronald Heiner, que parecem propor solução promissora, e cita também alguns estudos de sociobiologistas — Jack Hirchleifer (1987) — sobre a questão dos problemas motivacionais. Sugere também, por várias vezes, a importância de uma teoria sociológica do conhecimento - leia-se teoria da ideologia — para o entendimento da evolução econômica. Argumenta que o estudo da interação entre Reality and Beliefs (North, 1999: 10) é crucial para a explicação da evolução das sociedades no longo prazo. Vejamos um pouco mais acerca de suas idéias sobre esse tema.

$\mathrm{Na}$ ausência de uma racionalidade otimizadora substantiva, resta ao autor explorar mais a fundo a formação das crenças dos agentes que estão por trás das tomadas de decisão. Em outros termos, entender o papel da ideologia (interconnected comprehensive view of the world, em North, 1981: 52) nas sociedades signifi$\mathrm{ca}$ "the single most important step that research in the social sciences can make to replace the black box of the "rationality" assumption used in economics and rational choice models" (Denzan e North, 1994: 2).

Ao restringir o comportamento individualista, resultante de um cálculo maximizador puro e simples, funciona como uma importante instituição informal na sociedade. Reduz, portanto, a incerteza na interação entre as pessoas, estabelecendo uma base comum de crenças e regras que permitirão as trocas econômicas. O caráter disciplinador das ideologias reduz os custos de transação (ver North, 1981: 11).

Altera o significado clássico do conceito de ideologia. Argumenta North que códigos morais e éticos de conduta, fortemente baseados em ideologias, estão na base da estabilidade social, sendo responsáveis pelo funcionamento do sistema econômico (North, 1981: 47). Ideologias, ao sustentarem regras informais, também contribuem fortemente para a manutenção das leis e códigos escritos de uma sociedade através de um efeito legitimador. São estáveis as leis que parecem legítimas aos agentes.

A introdução de ideologia na análise econômica também é útil para explicar um outro paradoxo da teoria neoclássica. Segundo North, a defesa da idéia de um estado hobbesiano, como resultante de um acordo entre agentes que produza regras ótimas de interação social, é conflitante com um cálculo maximizador simplista praticado pelos agentes segundo a teoria. Se o agente é racional quanto ao seguimento do acordo hobbesiano, deixa de sê-lo em relação à maximização de seus custos e benefícios individuais (North, 1981: 45). Novamente defende o autor a importância das ideologias para explicar situações desse tipo. Procura mostrar que somente a partir do estudo da dinâmica ideológica das sociedades podemos entender comportamentos coletivos que parecem infringir a restrição da maximização individual. Reconhece, portanto, a lógica do free rider, mas propõe uma espécie de “racionalidade ideológica” para superá-la (North, 1981: 47).

Além da importância na sustentação de regras informais, as ideologias têm grande influência na constituição das regras formais de uma sociedade. Ao impregnar a tomada de decisão dos agentes políticos, estão também na base da formação de nossos códigos escritos; as ideologias importam para o entendimento das regras e leis que derivam do funcionamento do sistema político. Seja no comportamento de go- 
vernantes, de grupos de interesse ou ainda de agentes do sistema judiciário, é somente por meio do conceito de ideologia que podemos entender a construção do arcabouço legal de uma sociedade (North, 1981: 56-57). As ideologias estão na base da formação das regras formais e informais de uma sociedade e, portanto, têm papel fundamental no desempenho das diversas economias (ver North, 1999: 14-15).

Para concluir, vejamos brevemente o pequeno modelo da dinâmica de ideolo-

gias que North propõe. Curiosamente, inspira-se na A Estrutura das Revoluções Científicas, de Thomas Kuhn (Kuhn, 1976), para explicar o surgimento e desaparecimento de ideologias. Propõe que a dinâmica ideológica é parecida com a dinâmica científica proposta por Kuhn. A manutenção de uma ideologia depende de sua capacidade de explicar o mundo à sua volta e da ausência de ideologias competidoras com maior poder explicativo - uma espécie de "ideologia paradigmática". Com o surgimento de novas ideologias e com a acumulação de "anomalias ideológicas" os agentes podem migrar para uma nova visão de mundo, abandonando a antiga, caracterizando o que Kuhn chamou de revolução científica (Kuhn, 1976: 145-6) — revolução ideológica no caso de North. Uma ideologia só se sustenta se for capaz de explicar coerentemente o mundo à sua volta. É, portanto, uma racionalização de fenômenos reais percebidos (North, 1981: 49).

\section{O Estado e sua relação com a economia}

O Estado tem importância central nas idéias de North. Na medida em que define e cuida do enforcement da base legal de uma sociedade, responde diretamente pela manutenção e formação de suas regras formais. Ao definir a estrutura de propriedade sobre o que é produzido, condiciona desde o início o a performance das economias. A própria definição de Estado para North está umbilicalmente ligada à idéia de direitos sobre propriedade e regras de produção (North, 1981: 21).

Ele argumenta que as tradicionais teorias do Estado estão incompletas por não tratarem adequadamente da questão da evolução das formas de propriedade. A teoria do Estado marxista ou explorador, que atua defendendo os interesses das classes no poder, ignora os ganhos econômicos iniciais obtidos pelo pacto que faz surgir o Estado. A teoria contratualista, por sua vez, explica esses ganhos, mas menospreza a tendência de determinados grupos tomarem conta do Estado.

A dinâmica básica do modelo de Estado proposto por North vem da interação das atitudes de um ruler e de seus constituents. O primeiro busca maximizar suas receitas a partir de regras que define sobre a propriedade e a produção dos constituents. Estes, por sua vez, cedem parte de seus direitos ao Estado em troca de serviços como proteção e justiça. O limite de submissão dos constituents ao ruler vem do custo de oportunidade enfrentado pelos mesmos de se manter sob a égide de um dado ruler. Se por algum motivo outro Estado - ou algum arranjo dentro do próprio Estado - for capaz de oferecer os mesmos serviços a um custo tributário menor, haverá a tendência de dissolução do governo e deposição do ruler (North, 1981: 23).

Dessa dinâmica resultará a estrutura de propriedade da economia. Será mais 
eficiente - discutiremos esse conceito com o devido cuidado mais adiante - quanto maior for o poder dos constituents em restringir as atividades de taxação dos rulers. Será ineficiente quanto maior a força dos governos em impor regras de apropriação dos excedentes que resultem em desestímulo à produção de riqueza (North, 1981: 25).

Ao definir as instituições formais no modelo, o estado determina "the fundamental rules of competition and cooperation which will provide a structure of property rights (that is, specify the ownership structure in both factor and product markets) for maximizing the rents accruing to the ruler... [and] reduce transaction costs in order to foster maximum output of the society and, therefore, increase tax revenues accruing to the state" (North, 1981:24). É somente a partir do estudo do funcionamento do sistema político que podemos entender a origem e a dinâmica das regras formais em uma sociedade.

É importante frisar que North parte de um modelo simples, desenvolvido no texto de 1981, para entender a dinâmica básica entre a esfera política e econômica das sociedades. No texto de 1990, enriquece sua análise, estendendo o modelo para formas de Estado com vários grupos de interesse, e não um simples ruler, tocando inclusive na questão da evolução dos sistemas políticos para formas democráticas. Não é de nosso interesse aqui desenvolver todas essas idéias. Basta reter seu ponto principal que está na análise da interação entre a política e a economia. Vejamos.

Um sistema político ideal seria aquele que produzisse uma estrutura de propriedade que maximizasse o produto econômico de uma sociedade. Seria, portanto, um sistema capaz de produzir uma estrutura eficiente de propriedade como veremos abaixo - um sistema político eficiente. Destaca que a democracia é um grande avanço nesse sentido, mas não constitui necessariamente uma situação dessas, alertando para os perigos da transposição da lógica econômica para o mercado político. A democracia não equivale, na política, aos mercados competitivos em economia (North, 1990: 51). Argumenta que a imperfeição do mercado político está na base da constituição de instituições econômicas ineficientes. Defende que os custos de transação também são altos na política, dificultando um funcionamento adequado do sistema (North, 1990: 109). Apesar de não ter uma teoria completa sobre esse tema, sugere pontos relevantes, apontando o caminho que acredita ser o correto (ver North, 1990: 112).

\section{O conceito de eficiência e o sistema de propriedade}

O conceito-chave para o entendimento da prosperidade proposta por North é o de instituições eficientes. O autor define, já no livro de 1973, um arranjo institucional deste tipo: capaz de igualar o retorno privado ao retorno social das atividades econômicas dos agentes de uma dada sociedade. Uma matriz institucional eficiente será aquela capaz de estimular um agente ou organização a investir numa atividade individual que traga retornos sociais superiores a seus custos sociais. A chave para tal arranjo de sucesso está em estabelecer um sistema de propriedade 
bem definido e acompanhado de um aparato de enforcement eficaz (North e Thomas, 1973: 1-2).

Ao definir e garantir direitos de propriedade, arranjos eficientes levarão organizações e indivíduos a investir em atividades economicamente produtivas, notadamente na acumulação de capital e conhecimento. Por várias vezes e em vários de seus textos, North dá exemplos específicos dessas formas institucionais e organizacionais: "Joint stock companies, corporations... prizes, patent laws... enclosures, bills of exchange, the abolition of serfdom... insurance companies" (North e Thomas, 1973: 5 - para uma descrição mais detalhada ver também North, 1997: 27-29). Vejamos um pouco mais acerca da evolução dessa idéia na obra de North.

No texto de 1973, ele ainda tem uma visão simplista do surgimento das formas de propriedade. Argumenta que cálculos de custo-benefício de criação e manutenção estariam por trás da definição das mesmas, em outros termos, relações de escassez ou abundância de fatores de produção determinariam em cada caso a estrutura de propriedade (North, 1990: 51). Já na obra de 1981, amplia seu raciocínio, abrindo espaço para as formas de governo determinarem a estrutura de propriedade. Como vimos acima, da interação entre os governantes e seus governados resultaria a base legal determinante dessa estrutura. Abandona, portanto, uma visão mais otimista, na qual instituições eficientes surgiriam como respostas econômicas automáticas, para adotar uma postura mais pessimista, na qual governos, ao maximizar suas receitas tributárias, poderiam produzir arranjos institucionais ineficientes, em outros termos, sistemas de propriedade mal definidos.

$\mathrm{Na}$ obra de 1990 vai além. Amplia seu modelo de Estado, para encontrar no mau funcionamento dos sistemas políticos atuais a causa do surgimento e persistência de arranjos de propriedade ineficientes. Soma a esse argumento a importância das ideologias, para então concluir que um arranjo eficiente depende, em última análise, da dinâmica política e cultural de uma sociedade (North, 1990: 140).

Num outro plano, também percebemos uma evolução na idéia de eficiência. Ele trabalha inicialmente com um conceito de eficiência produtiva, "como a capacidade de se gerar um certo arranjo institucional que maximize a produção, dado um certo estoque de recursos e tecnologia" (Moraes Junior, 2000: 10) - como visto acima, idéia fortemente presente nos livros de 1973 e 1981. Introduz no texto de 1990 um conceito mais elaborado, eficiência adaptativa. Uma sociedade será mais eficiente quanto maior for sua capacidade de se adaptar a adversidades ao longo do tempo (Moraes Junior, 2000: 10). Migra, portanto, de uma concepção estática de eficiência para uma dinâmica (ver North, 1990: 80).

\section{O MODELO DE 1990}

Por fim, chegamos ao cerne da contribuição do autor. No texto Institutions, Institutional Change and Economic Performance, North finalmente atinge seu objetivo. Se descola da história, para enunciar um modelo do desenvolvimento econômico. Segundo suas palavras (North, 1990: 7), encontra a resposta teórica que 
procurava. Em nossos termos, opera sua transição final da análise histórica para a teórica (ver Velasco e Cruz, 2001: 5).

Abandona o estudo da evolução das instituições como a forma histórica pela qual os homens estabeleceram a ordem social. Amplia o insight de Ronald Coase - "when it is costly to transact, institutions matter" (North, 1990:12) — para teorizar sobre as reduções de custos de transação que instituições trazem para um sistema econômico em termos hipotéticos. Alguns comentários importantes antes de entrar no modelo propriamente dito.

Ao longo do percurso, percebemos que a busca do entendimento do progresso econômico em North se mistura com a busca pela compreensão da evolução das instituições que levam a esse progresso. Para o autor, estudar o desenvolvimento econômico significa, portanto, estudar o desenvolvimento institucional. Não à toa, sua obra mais importante se preocupará em entender a dinâmica institucional das sociedades. Após 20 anos de trabalhos e estudos, conclui que não é possível entender a evolução e o progresso das sociedades sem uma teoria das instituições.

Apesar de discursar num nível teórico, faz questão de aplicar sua proposta, ao longo do texto, a análises históricas. Discute a evolução da economia norte-americana no século XIX (North, 1990: 8), o papel da Northwest Ordinance, que regulou a ocupação das terras do Oeste nos Estados Unidos ainda no século XVIII (North, 1990: 97), a dissolução do feudalismo (North, 1990: 89 e 96), a permanência de economias regionais primitivas como o Suq (North, 1990: 123), as diferentes trajetórias históricas da América do Norte e América Latina (North, 1990: 103 e 113), o impacto da Revolução Gloriosa na história inglesa (North, 1990: 139), entre outras. Vejamos o modelo que propõe.

\section{Incerteza}

O conceito mais fundamental ou primário do modelo é a incerteza. A existência desta, argumenta o autor, impossibilita ou dificulta enormemente a possibilidade de transações econômicas entre pessoas. North está aqui primordialmente preocupado com situações de imperfeição de informação presentes nos settings de escolha e de interação dos agentes.

Não é completamente explícito a respeito do tipo de incerteza com que os agentes se deparam. Por momentos (North, 1990: 25) podemos considerar que o autor tem basicamente uma visão de incerteza epistemológica como definida por Davidson (1996: 5), significando que os agentes não possuem as capacidades mentais e computacionais para conhecer e processar todas as informações pertinentes à sua tomada de decisão. Prova dessa postura está em sua defesa de uma racionalidade processual do tipo Herbert Simon, em geral associada a esse primeiro tipo de caracterização de incerteza (no que Dequech, 2001(a): 6, tipifica incerteza procedimental ou processual).

Mais recentemente (North, 1999: 16), encontramos indícios de que North tem em mente uma noção mais forte de incerteza, não se referindo apenas a problemas computacionais dos agentes, mas sim a uma situação de realidades mutáveis. Po- 
deríamos aí então considerar esse tipo de incerteza como ontológica nos moldes da definição de Davidson (1996: 494) — em outros termos, a relevância do conceito de não-ergodicidade no setting informacional dos agentes. (Para uma discussão mais detalhada sobre esse assunto, ver Dequech, 2001a.)

Seja ontológica, seja epistemológica, o que interessa é a utilidade do conceito de incerteza para o ferramental de North. Ao impedir que os agentes conheçam todo o seu rol de possibilidades de escolha de forma ex ante, esta se torna responsável por interrupções ou "mau funcionamento" das transações econômicas, fazendo com que os agentes sejam incapazes de atingir soluções ótimas a partir de suas decisões.

\section{Custos de Transação}

Nesta parte do modelo, North reduz o grau da abstração de seu discurso, para explicitar o que de fato o interessa derivar do conceito de incerteza: os custos de transação.

Grosso modo, estes se dividem em dois. Custos de measurement e de enforcement. O primeiro relaciona-se à dificuldade dos agentes em conhecer de fato o objeto da transação em curso (North, 1990: 29). Tem, obviamente, um quê da literatura dos problemas de assimetria de informação, notadamente da linhagem Akerlof e The Market for Lemons. O ponto crucial aqui está na impossibilidade do conhecimento da qualidade do produto de forma ex ante pelo agente comprador em uma transação; fato que, no limite, pode abortar a troca, anulando possíveis ganhos de comércio.

Os custos de enforcement, por sua vez, referem-se à incerteza que os agentes têm sobre a propriedade do bem a ser trocado (North, 1990: 32) e, portanto, relacionam-se a problemas de legitimidade da transação a ser efetuada. A preocupação aqui se volta a transações complexas que envolvem bens consumidos e produzidos ao longo do tempo, e não meramente a trocas simples e únicas. Se algum tipo de arcabouço de proteção não estiver presente de forma a minimizar esse tipo de incerteza, veremos que, novamente, as trocas entre agentes não serão possíveis.

Enfim, a partir desses dois conceitos, North procura mostrar a dificuldade enfrentada pelos agentes econômicos por conta da existência de incerteza. A partir daí, introduz o conceito de instituições, que será a base de todo o seu modelo. Estas, ao reduzirem os custos de transação, atenuando o problema da incerteza, facilitarão a coordenação econômica e social (North, 1990: 27).

Uma nota aqui já se faz importante. Não há nada que garanta, para North, uma evolução institucional que aumente a eficiência das economias. Voltaremos a este ponto mais adiante.

\section{Instituições}

Chegamos ao cerne do modelo. Na presença de incerteza e para superar os custos de transação surgem as instituições. Desde os primórdios até hoje, indivíduos 
interagem a partir de regras. Somente a partir do surgimento destas, é possível entender a organização das sociedades (ver North, 1990: 3).

O nível de abstração do conceito de instituição é de fato alto. Uma regra ou norma que rege a interação entre indivíduos pode ter infinitos significados. Para tornarmos o conceito mais útil, devemos reduzir seu nível de abstração, como faz North. Ele aplica-o de forma específica ao campo da economia, notadamente na intermediação de interações econômicas entre agentes. Nessa linha pode-se fazer a leitura de que as instituições representam uma restrição a mais para os agentes no curso de suas transações econômicas. Desta maneira, estaríamos, contudo, reduzindo demais seu papel no arcabouço de North. Como argumenta Dequech (2001b: 8) as instituições podem jogar também um papel construtivo, e não meramente restritivo, na interação dos indivíduos.

Importante também é a divisão destas em formais e informais. Sendo as primeiras leis e constituições formalizadas e escritas, em geral impostas por um governo ou agente com poder de coerção (North, 1990: 46), e as segundas, normas ou códigos de conduta, formados em geral no seio da própria sociedade (North, 1990: 36).

\section{Organizações}

Chegamos agora ao conceito que gera a dinâmica do modelo. A partir dos estímulos oferecidos pela matriz institucional, surgirão diversas organizações que atuarão na busca de diversos objetivos. Para North, organizações são os principais agentes de uma sociedade e dentro dessa categoria encontramos os mais diversos entes: "political bodies (political parties, the Senate, a city council, a regulatory agency), economic bodies (firms, trade unions, family farms, cooperatives), social bodies (churches, clubs, athletic associations), and educational bodies (schools, universities, vocational training centers)" (North, 1990: 5).

Para melhor explicar o papel destas no modelo, o autor lança mão da metáfora dos jogos esportivos. Se as instituições são as regras do jogo, as organizações representam os diversos times que disputam o campeonato da sociedade. North não se aprofunda muito no porquê do surgimento das organizações, limitando-se a fazer algumas referências aos trabalhos de Coase, Barzel e Williamson — que grosso modo explicam o surgimento destas como respostas ótimas à existência de custos de transação. Sua preocupação principal está em criar uma nova categoria de análise que possa introduzir dinâmica no sistema ao interagir com a matriz institucional (North, 1990: 4).

Originalmente, as organizações surgem do framework institucional de uma sociedade num momento do tempo. Daí por diante, passam a interagir com outras organizações, com as próprias instituições e com as tradicionais restrições da teoria econômica. Dessa interação resulta a economic performance das diversas sociedades, bem como sua evolução institucional. Vejamos isso com mais detalhes.

Ao longo do processo histórico, as diversas organizações podem investir seus esforços das mais variadas maneiras, sempre buscando na margem os maiores 
payoffs para suas ações. Podem investir em atividades econômicas socialmente produtivas - como em novas tecnologias de produção - , podem investir em atividades redistributivas - como, por exemplo, a formação de monopólios. Podem ainda investir na própria alteração das regras do jogo, mudando, portanto, a matriz institucional sob a qual estão operando (North, 1990: 78). Nada garante, entretanto, que esses investimentos sejam socialmente ótimos ou que exista algum mecanismo capaz de levá-los ao longo do tempo a uma situação eficiente.

A partir desse amplo processo de interação entre instituições e organizações, North procura entender a evolução das sociedades. Ao longo do texto de 1990 encontramos referência, entre outras, às seguintes organizações: Mafia, General Motors, Merchant Adventures, Manors, Pirates, Chemical manufacturer do século

XX. Ainda a respeito dessa interação, vale a pena mencionar a comparação que North faz da indústria química do início do século XX com atividades de piratas ao longo da história. Os primeiros, ao gerarem demanda por novos conhecimentos, estariam engajados em atividades produtivas e os segundos, ao saquear e roubar, estariam privilegiando atividades redistributivas. A explicação para o comportamento de ambos estaria nos incentivos contidos na matriz institucional de suas sociedades (ver North, 1990: 78).

\section{A Dinâmica da Matriz Institucional}

Ao abrigar as instituições - formais e informais — de uma sociedade num momento específico do tempo, a matriz institucional será responsável por definir o vetor de estímulos para os diversos agentes sociais, especialmente os envolvidos em atividades econômicas. Em grande parte, a história das sociedades se resume, para North, na evolução de suas matrizes institucionais e suas decorrentes consequências econômicas, políticas e sociais.

O conceito de matriz institucional procura dar operacionalidade à teoria, pois apresenta-se de forma mais concreta. Para entendermos o desempenho de diversas sociedades ao longo da história basta analisarmos a dinâmica de suas matrizes institucionais (North, 1990: 5).

Já vimos que os principais agentes de mudança no modelo de North são as organizações. É a partir destas também que podemos entender a dinâmica institucional que North propõe. Para maximizar o retorno de suas atividades, organizações investem, na margem, em atividades econômicas ou políticas. Ao se depararem com mudanças de preços relativos e preferências — ou algum tipo de mudança exógena ao ambiente econômico - , têm duas opções para capturar novas oportunidades de ganho: rearranjar a relação de insumos e produtos com que trabalham sem alterar a matriz institucional sob a qual operam ou investir esforços para mudar essa matriz de modo a poder capturar tais ganhos decorrentes de mudanças no ambiente.

Uma organização, ao operar, afeta variáveis políticas e econômicas. Quando seu cálculo de custo-benefício levá-la a atuar na esfera política, isto é, alterar leis, contratos e normas, assistiremos a uma mudança institucional. Para melhor expli- 
citar essa concepção, North introduz a noção de equilíbrio institucional (North, 1990: 86). Uma dada sociedade estará nesse equilíbrio quando, dada as condições correntes, nenhum de seus agentes (organizações) tiver estímulo para alterar as regras formais e informais (instituições) sob as quais essa sociedade opera (ver North, 1990: 86).

O segundo conceito essencial para a dinâmica institucional de North é o path dependence. Desenvolvida pelos trabalhos de Paul David e Brian Arthur, essa idéia procura demonstrar como soluções ineficientes podem persistir, mesmo que escolhidas por agentes racionais. Por conta de retornos crescentes, a escolha de uma tecnologia menos eficiente num dado momento do tempo acaba se tornando ótima quando o sistema é dinamizado. Em outros termos, a história do processo adquire relevância.

Como nos mostra North (1990: 94), os mecanismos self-reinforcing de Arthur ocorrem devido a quatro motivos principais: i) altos custos de set-up, ii) efeitos de aprendizado, iii) efeitos de coordenação e iv) expectativas adaptativas. A conseqüência deles é, na sequência: i) possibilidade de múltiplos equilíbrios, ii) possibilidade de equilíbrios ineficientes, iii) lock-in e iv) path dependence (ver North, 1990: 95).

A consequência dessa concepção da dinâmica institucional é a de que mudanças ocorrem de forma gradual, ao alterar na margem a estrutura de regras das sociedades. O próprio conceito de retornos crescentes realça a idéia de que uma vez numa trajetória, maior a tendência de permanência nela. A partir desse conceito, North procura confrontar a idéia otimizante de evolução institucional presente na proposta de Armen Alchian (para mais detalhes, ver North, 1990: 92). O início de um processo tem papel fundamental sobre o curso de seus acontecimentos. Com o passar do tempo instituições ineficientes não sucumbem. As decisões tomadas no passado têm, portanto, forte influência sobre as possibilidades do presente. Como diz North, antes de tudo um historiador econômico, history matters (North, 1990: 100).

\section{O Desempenho Econômico}

Vejamos finalmente como fica a "Teoria Geral" proposta por North (para uma formulação semelhante, ver Eggertsson, 1998: 8-11, Garcia et al, 1999: 9-10 e Medeiros, 2001: 78-80):

- O ambiente econômico e social dos agentes é permeado por incerteza.

- A principal consequiência dessa incerteza são os custos de transação. Estes podem ser divididos em problemas de measurement e enforcement.

- Para reduzirem os custos de transação e coordenar as atividade humanas, associedades desenvolvem instituições. Estas são um contínuo de regras com dois extremos: formais e informais.

- O conjunto dessas regras pode ser encontrado na matriz institucional das sociedades. A dinâmica dessa matriz será sempre path dependent. 
- A partir dessa matriz, definem-se os estímulos para o surgimento de organizações que podem ser econômicas, sociais e políticas.

- Estas interagem entre si, com os recursos econômicos - que junto com atecnologia empregada definem os transformation costs tradicionais da teoria econômica - e com a própria matriz institucional — que define os transaction costs - e são, portanto, responsáveis pela evolução institucional e pelo desempenho econômico das sociedades ao longo do tempo (ver North, 1990: 118 e North, 1999: 15).

\section{REFERÊNCIAS BIBLIOGRÁFICAS}

ABRAMOVAY, R. “Desenvolvimento e instituições: a importância da explicação histórica”, em Razões e Ficções do Desenvolvimento, Arbix, Zilbovicius e Abramovay (orgs.), Editora Unesp-Edusp, São Paulo, 2001.

BRESSER-PEREIRA, L. C. "Método e paixão em Celso Furtado", em A Grande Esperança em Celso Furtado, José Márcio Rego e Luiz Carlos Bresser-Pereira (orgs.), Editora 34, São Paulo, 2001.

CAPORASO, J.A. e LEVINE, D.P. Theories of Political Economy, Cambridge University Press, Cambridge, 1992.

DAVIDSON, P. "Reality and Economic Theory". Journal of Post Keynesian Economics, vol. 18(4), summer, 1996.

DENZAU, A. T. e NORTH, D. “Shared mental models: ideologies and institutions”, Kyklos, vol. 47, 1994.

DEQUECH, D. “Bounded rationality, institutions and uncertainity”, texto a ser publicado no Journal of Economic Issues, dez., 2001(a).

"Incerteza num sentido forte: significado e fontes", em Macroeconomia Moderna, Lima, Sicsú e de Paula (orgs.), Editora Campos, São Paulo, 1999.

"The new institutional economics and the theory of behaviour under uncertainty", texto do II Seminário Brasileiro da NEI, 2001(b).

EGGERTSSON T. "A note on the economics of institutions", em Empirical Studies in Institutional Change, Alston L., Eggertsson T., North D., (eds), Cambridge University Press, Cambridge, 1998 (1ed. 1996).

GARCIA, F., GOLDBAUM, S. VASCONCELOS, L., REBELO, A. "Instituições e crescimento: a hipótese do capital-efetivo", texto para discussão, FGV-SP, n 81, São Paulo, 1999.

GOldBAUM, S. O Postulado da Racionalidade e a Nova Economia Institucional: A Nova Teoria da Firma, Dissertação de Mestrado, FGV-SP, São Paulo, 1996.

GOLDIN, C. "Cliometrics and the Nobel", National Bureau of Economic Research, Historical Paper $\mathrm{n}^{\circ} 65,1994$.

HOBSBAWN, E. "Historiadores e economistas: II", em Eric Hobsbawn sobre História, Companhia das Letras, São Paulo, 1997.

KUHN, T. A Estrutura das Revoluções Científicas, Editora Perspectiva, São Paulo, 1976.

LAKATOS, I. "O falseamento e a metodologia dos programas de pesquisa científica”, em A Crítica e o Desenvolvimento do Conhecimento, Lakatos e Musgrave (orgs.), Cultrix-USP, São Paulo, 1979.

MACEDO, B.G. "A concepção de história em Douglass North e na economia do desenvolvimento", texto do II Seminário Brasileiro da Nova Economia Institucional, Campinas, 2001.

MEDEIROS, C.A. "Rivalidade estatal, instituições e desenvolvimento econômico", em Polarização mundial e crescimento, José Luís Fiori e Carlos Medeiros (orgs.), Editora Vozes, Petrópolis, 2001.

MORAES JUNIOR, A.C. "O Conceito de Eficiência na Nova Economia Institucional”, trabalho apresentado em Congresso, ANPEC, 2000.

NORTH, D. Structure and Change in Economic History, Norton, New York, 1981. 
NORTH, D. Institutions, Institutional Change and Economic performance, Cambridge University Press, Cambridge, 1990. e THOMAS, Robert P. The Rise of the Western World: A New Economic History, Cambridge University Press, Cambridge, 1973.

. "Structure and performance: the task of economic history", Journal of Economic Literature, 16, 1978.

e DAVIS, L. Institutional Change and American Economic Growth, Cambridge University Press, Cambridge, 1971.

. "Autobiography", The Bank of Sweden Prize in Economic Sciences in Memory of Alfred Nobel, 1993. . "Understanding the process of Economic Change", Iea Occasional Paper, London, 1999.

"Epilogue: economic performance through time", em Empirical Studies in Institutional Change, Alston L., Eggertsson T., North D., (eds.), Cambridge University Press, Cambridge, 1998 (1ed. 1996).

The Economic Growth of the United States 1790-1860, WW Norton \& Company, New York, 1966 (originalmente publicada em 1961, Prentice Hall).

"Institutions, transaction costs, and the rise of merchant empires", em The Political Economy of Merchant Empires, State Power and World Trade 1350-1750, James D. Tracy (ed.), Cambridge University Press, Cambridge, 1997, (1ed. 1991).

RUTHERFORD M. Institutions in Economics, the Old and the New institutionalism, Cambridge University Press, Cambridge, 1994.

TOYOSHIMA, S. "Instituições e desenvolvimento econômico: uma análise crítica das idéias de Douglass North", IPE-USP, Estudos Econômicos, vol. 29, n 1, 1999.

VAYNE, P.M. Como se faz a História, Editora UnB, Brasília, 1993.

VELASCO e CRUZ, S.C. "Teoria e história: nota crítica sobre o tema da mudança institucional em Douglass North", texto do II Seminário Brasileiro da Nova Economia Institucional, Campinas, 2001. 